\title{
Conventional cardiac surgery in patients with end-stage coronary artery disease: yesterday and today
}

\author{
Michal Szlapka ${ }^{1}$, Roland Hetzer², Jürgen Ennker ${ }^{3}$, Harald Hausmann ${ }^{1}$ \\ ${ }^{1}$ Department of Cardiac and Vascular Surgery, MediClin Heart Center Coswig, Coswig, Germany; ${ }^{2}$ Department of Cardiothoracic and Vascular \\ Surgery, Immanuel Cardio Centrum Berlin, Berlin, Germany; ${ }^{3}$ Department of Cardiac and Vascular Surgery, Heart Center Niederrhein, Krefeld, \\ Germany \\ Contributions: (I) Conception and design: R Hetzer, H Hausmann, M Szlapka; (II) Administrative support: J Ennker, H Hausmann; (III) Provision of \\ study materials or patients: R Hetzer, J Ennker, H Hausmann; (IV) Collection and assembly of data: M Szlapka, H Hausmann; (V) Data analysis and \\ interpretation: All authors; (VI) Manuscript writing: All authors; (VII) Final approval of manuscript: All authors. \\ Correspondence to: Harald Hausmann, MD, PhD. Department of Cardiac and Vascular Surgery, MediClin Heart Center Coswig, Lerchenfeld 1, 06869 \\ Coswig, Anhalt, Germany. Email: harald.hausmann@mediclin.de.
}

\begin{abstract}
Surgical therapy of combined coronary artery disease (CAD) and heart failure, also referred to as end-stage CAD, has evolved throughout the years and patients are currently being offered traditional coronary artery bypass grafting (CABG), with or without surgical ventricle restoration (SVR), interventions for ischemic mitral valve regurgitation, heart transplantation or implantation of mechanical cardiovascular support systems. Among surgical methods, operative myocardial revascularization (with or without ventricle restoration) is still playing an important role, aiming at restoration of proper myocardial perfusion, especially if heart muscle viability is present. Facing the donor shortage, CABG may constitute a valuable alternative to transplantation in selected patients. In individuals considered not suitable for surgical revascularization, implantation of mechanical circulatory support (MCS) not only appears as a salvage procedure, but also allows for reevaluation of future therapy directions. This article aims at providing an overview of evolving and current surgical practices in patients with end-stage CAD.
\end{abstract}

Keywords: Coronary artery bypass grafting (CABG); end-stage coronary artery disease (CAD); heart transplantation ischemic cardiomyopathy; myocardial viability; surgical ventricle restoration (SVR)

Submitted Feb 15, 2020. Accepted for publication Apr 22, 2020.

doi: $10.21037 /$ cdt-20-284

View this article at: http://dx.doi.org/10.21037/cdt-20-284

\section{Introduction}

Patients with coronary artery disease (CAD) undergoing myocardial revascularization, with concomitant heart failure defined by left ventricular ejection fraction (LVEF) lower than $35 \%$, constitute a population at risk of poor long-term prognosis and limited survival (1). According to Topkara et al., among $\mathrm{CAD}$ patients referred for coronary artery bypass grafting (CABG) procedure, nearly $35 \%$ presented with $\mathrm{EF}$ of $40 \%$ or less. In-hospital mortality in these individuals was related to the extent of left ventricular (LV) dysfunction, reaching up to $6.5 \%$ in the group with EF between $10 \%$ and $20 \%$ (1). According to Hausmann et al. (2), even in a high- volume center the operative mortality in patients with endstage CAD in the late 1980s was disastrous (ca. $25 \%$ in 1986), though throughout the years it could be substantially reduced to $3.1 \%$ in 2000 , reflecting obvious improvements in surgical technique and postoperative care. Survival at 10 years (Figure 1) reached $51 \%$ (2).

According to the landmark Coronary Artery Surgery Study (CASS) from the early 1980's of the 20th century, 5 -year survival in CAD patients with heart failure was poor (38\%), though CABG was shown to be a treatment modality offering promising results with acceptable risk, compared to medical therapy. Among study participants, 5-year survival after CABG reached $63 \%$, but only $43 \%$ in patients treated 


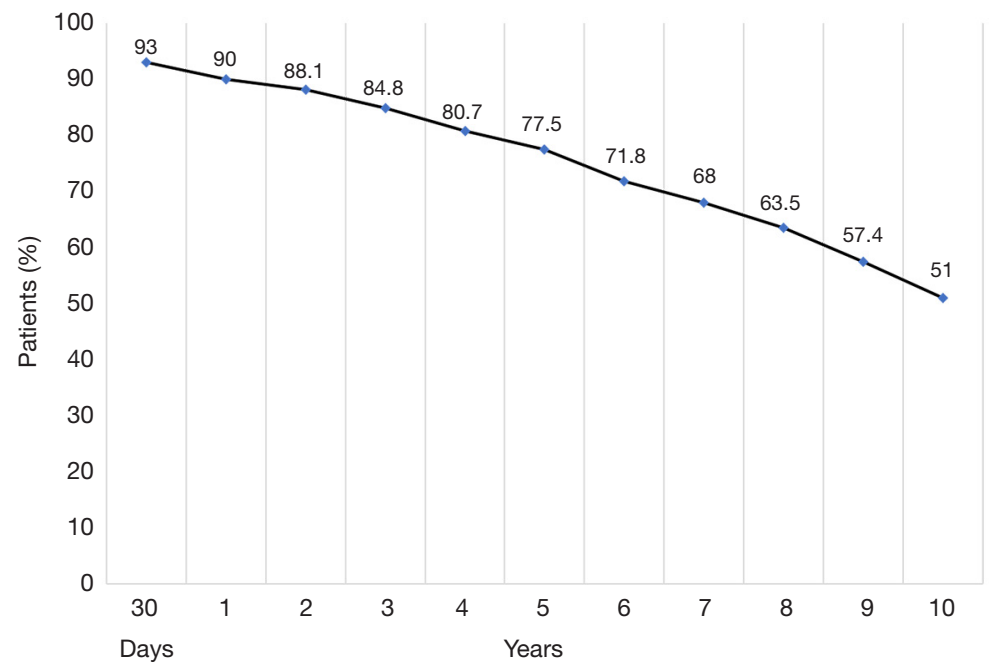

Figure 1 Survival rates after CABG in patients with LVEF <30\% in a high-volume European cardiac surgery center (German Heart Center Berlin, observational study on 2,158 patients, operated on between 1986 and 2003). CABG, coronary artery bypass grafting; LVEF, left ventricular ejection fraction.

conservatively (3). Two years later, Passamani et al. (4) reported survival at 7 years of $84 \%$ after CABG, compared to $70 \%$ in patients undergoing only medical therapy. It is worth mentioning, however, that the number of patients with EF less than $50 \%$, enrolled in the CASS study, was relatively low (5). Currently, long-term mortality from cardiovascular reasons during a mean follow-up of 9.4 years in end-stage CAD patients has been reported to be $40 \%$ in CABG and $49 \%$ in those treated medically, showing superiority of operative revascularization over conservative treatment in terms of increased survival (6).

Nowadays, surgical therapy of end-stage CAD patients comprises operative myocardial revascularization (CABG), with or without surgical ventricle restoration (SVR), surgical intervention for ischemic mitral valve regurgitation, implantation of mechanical circulatory support (MCS) and heart transplantation.

\section{Surgical approaches in end-stage CAD}

\section{Myocardial revascularization: changing guidelines}

Since the beginning of the 21 st century, recommendations regarding myocardial revascularization in patients with end-stage CAD have evolved substantially. Previously, European guidelines on surgical CAD therapy focused predominantly on coronary artery anatomy and disease distribution. Presently, they reflect a growing understanding of CAD complexity and emphasize the role of interdisciplinary decision making, which enables choosing less invasive interventional solutions in patients with unacceptable high risk, who are not suitable for surgical revascularization. Changing approach to CAD patients has been a consequence of recently published SYNTAX and EXCEL trials $(7,8)$. The main goal of the SYNergy between percutaneous coronary intervention with TAXus and cardiac surgery (SYNTAX) study was to randomly compare the efficacy of two therapeutic modalities, i.e., CABG vs. percutaneous coronary intervention (PCI), for treatment of coronary three-vessel disease with or without stenosis of the left main (LM) coronary artery. The Evaluation of XIENCE versus Coronary Artery Bypass Surgery for Effectiveness of Left Main Revascularization (EXCEL) trial shared similar investigation principle with the SYNTAX study but focused specifically on patients with LM coronary disease. To enable evaluation of CAD complexity, the SYNTAX investigators came up with a SYNTAX score, which involved assessment of:

(I) Coronary dominance;

(II) Number of lesions;

(III) Segments involved per lesion, with lesion characteristics;

(IV) Total occlusions with subtotal occlusions;

(V) Trifurcation, number of segments diseased;

(VI) Bifurcation type and angulation;

(VII) Aorto-ostial lesions; 
(VIII) Severe tortuosity;

(IX) Lesion length;

(X) Heavy calcification;

(XI) Thrombus;

(XII) Diffuse disease, with number of segments.

The Guidelines of the European Society of Cardiology/ European Association of Cardio-Thoracic Surgery from 2010 on therapy of CAD in patients with heart failure recommended surgical revascularization for significant LM coronary artery stenosis or its equivalent, as well as for proximal LAD stenosis, accompanied by double or triple coronary disease (9). In subsequent guideline version from 2014 (10) LM stenosis remained an indication for surgical intervention, but then 4 years later, class I recommendation (11) relied upon predicted 'revascularization suitability' of coronary targets and consideration of acceptable risk, rather than on stenosis location. In addition, recent guidelines (11) considered growing potential of PCI as alternative to CABG in end-stage CAD with multivessel disease, provided that complete revascularization could be achieved. Nevertheless, lessons learned from the SYNTAX trial indicate that despite growing CAD population treated with PCI, CABG remains a gold standard of care, offering durable and complete revascularization, less need for repeat interventions and lower rate of late ischemic events (12). Regarding the EXCEL trial, which suggested no major differences in 5-year composite outcome of death, stroke and myocardial infarction between PCI and CABG strategies, there has been recently a concern of unreported myocardial infarction rate in the PCI study arm. As a result, the EACTS and ESC Guidelines Committees withdrew their support for recommending PCI in patients with $\mathrm{LM}$ stenosis and low/intermediate lesions complexity, as assessed by the SYNTAX score (13).

The reason for the overall lower rate of late ischemic events in patients undergoing CABG, compared to PCI, might be explained by the differences in revascularization mechanisms between these two methods of intervention. While PCI restores flow caused by flow-limiting coronary lesions, CABG provides an additional anti-ischemic effect by creating 'surgical collateralization', thus protecting patients from late myocardial infarctions resulting from not flow-limiting coronary stenoses (14).

\section{$S V R$}

Similar to recommendations for isolated CABG in endstage CAD, the guidelines regarding SVR have also been a subject of change within the last decades. European Guidelines on myocardial revascularization from 2010 recommended consideration of concomitant CABG and SVR, if a substantial dilation of left ventricle [Left Ventricle End-Systolic Volume Index (LVESVI) $\left.>60 \mathrm{~mL} / \mathrm{m}^{2}\right]$ and scarred left anterior descending (LAD) territory were present (9). Subsequent guidelines from 2014 suggested performing SVR in patients with 'large ventricle aneurysm' at risk of rupture, thrombus formation and life-threatening arrhythmias. However, the guidelines did not provide precise parameters to define the term 'large aneurysm'. SVR, combined with CABG was also justified whenever reduction of LVESVI (values lower than $70 \mathrm{~mL} / \mathrm{m}^{2}$ ) could be achieved (10).

In 2018, the indication for simultaneous CABG and SVR remained valid for 'large aneurysm' in patients presenting symptoms of advanced heart failure (NYHA III/IV), in presence of intraventricular thrombus and arrhythmias. According to Guidelines, SVR and CABG should be performed in selected patients in centers of expertise (11).

The aim of SVR is to recreate physiologic, elliptical shape of left ventricle and to eliminate as much scarred and dysfunctional tissue as possible. Studies from late 1990's showed a clear relationship between enlarged left ventricle and increased mortality (15). At the end of the 20th century, several surgical techniques emerged, aiming at exclusion of diseased left ventricle regions. One of the methods, partial elimination of diseased posterior $\mathrm{LV}$ regions introduced by Batista (16), was euphorically welcomed though late results turned out to be disappointing. The methodological failure of this surgical concept appeared to be related to improperly identified target areas for $\mathrm{LV}$ reconstruction $(16,17)$. Subsequently, a concept of 'site selection', based on echocardiographic detection of dysfunctional LV regions was promoted by several authors, who indeed were able to observe improvement of surgical results of posterior resection together with reduced mortality $(18,19)$. Regarding SVR after anteroseptal myocardial infarction, the group of Dor, followed by the Reconstructive Endoventricular Surgery returning Torsion Original Radius Elliptical shape to the left ventricle (RESTORE) investigators, reported on promising results of anteroseptal ventricle reconstruction. In this international registry of more than 1,000 patients with post-infarction congestive heart failure, SVR proved its efficacy in terms of providing substantial increase of left ventricle function, restoring of physiological LV-dimension and shape and improvement of clinical status, as assessed by the NYHA classification 


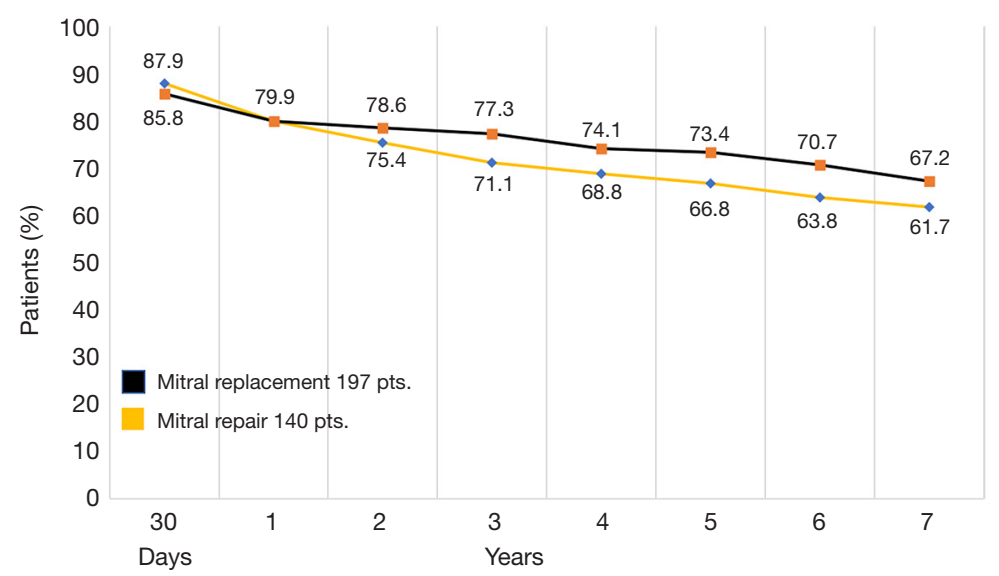

Figure 2 Differences in long-term survival between patients undergoing surgical mitral valve repair vs. replacement for ischemic mitral valve insufficiency. pts., patients.

\section{$(17,20,21)$.}

The above-mentioned reports were published by centers of SVR expertise, but studies validating utility and safety of restoration concept in a randomized and prospective fashion were lacking. The Surgical Treatment of Ischemic Heart failure trial (STICH) was supposed to answer the question whether there was a real benefit of SVR added to revascularization in patients with end-stage CAD (22). Some methodological concerns, such as changing enrollment criteria during prolonged patient recruitment or lacking identification of scared territories made the study a subject of deserved criticism $(23,24)$. In contrast to STICH investigators, Dor and his group provided clear description of preoperative volumetric and viability assessment, which were crucial for procedure success. Dor et al. were very convincing, showing obvious advantages of precise preoperative evaluation, which, in their opinion, reduced number of ICM patients denied proper surgical treatment (24). Nevertheless, the guidelines in the 'after STICH trial era' became more restrictive regarding indication to simultaneous CABG and SVR.

Recently, there have been several methods of minimally invasive ventricle restoration techniques introduced, reflecting a current trend towards minimalization of surgical procedure invasiveness. One of them, interventionallyimplanted endocardial Parachute device, first introduced in 2014, was shown to significantly reduce left ventricle volume, as well as to improve EF and functional NYHA class (25). In 2017, a review article summarizing previous experience with this novel device was published, showing quite high implantation success (over 90\%) and promising postprocedural results in terms of reduction of $\mathrm{LV}$ volumes and improvement of EF (26). In 2019, an experience with hybrid ventricle restoration anchoring device, mimicking ventricular plication, was presented by 2 clinics from Netherlands. Preliminary results of device application in a hybrid fashion were quite promising, with $0 \%$ periprocedural mortality and 100\% implantation success (27).

\section{Interventions for ischemic mitral valve regurgitation}

A relevant portion of patients with end-stage CAD suffered from severe mitral incompetence (28). In a nonrandomized study on surgery for ischemic mitral regurgitation, Hausmann and colleagues observed no difference in early or late survival in 197 treated with CABG combined with mitral replacement and 140 patients treated by CABG and mitral repair (29) (Figure 2). Seven-year survival was $67 \%$ and $62 \%$, respectively, although it was better among patients who had no or minimal mitral regurgitation after repair (77\% at seven years) than among those who had more extensive regurgitation after repair or mitral replacement (30) (Figure 3).

\section{Myocardial viability and its impact on treatment results}

$\mathrm{LV}$ dysfunction in end-stage CAD patients may result from both irreversible and reversible myocardial damage. In case of the latter condition, also referred to as 'hibernating myocardium' (31), a proper myocardial function is likely to be restored by myocardial revascularization. Within the last 


\begin{tabular}{|l|llllll|}
\hline $\begin{array}{l}\text { Living } \\
\mathrm{n}=94\end{array}$ & $\begin{array}{l}\text { Residual MI } \\
1 .\end{array}$ & $\begin{array}{l}0 \\
\mathrm{n}=28\end{array}$ & $\begin{array}{l}\text { I } \\
\mathrm{n}=60\end{array}$ & $\begin{array}{l}\text { II } \\
\mathrm{n}=21\end{array}$ & $\begin{array}{l}\text { III } \\
\mathrm{n}=14\end{array}$ \\
\cline { 2 - 6 } & pts. (\%) & 92.9 & 85.0 & 52.4 & 42.9 & - \\
\hline $\begin{array}{l}\text { Died during follow-up } \\
\mathrm{n}=29\end{array}$ & pts. (\%) & 7.1 & 15.0 & 47.6 & 57.1 & - \\
\hline
\end{tabular}

Figure 3 Influence of residual mitral valve insufficiency on survival at 7 years after mitral valve repair for ischemic mitral valve regurgitation. Observational study on 123 patients with ischemic mitral valve regurgitation. MI, mitral insufficiency.

decades, the value of myocardial viability assessment has been re-examined. The European Guidelines on Myocardial Revascularization from 2010 (9) showed a clear benefit of revascularization therapy in patients with preoperatively preserved myocardial viability. Clinical evidence supporting beneficial influence of present viable myocardium on therapy results came from a meta-analysis by Allman et al. (32). In 2014 and 2018 (10,11), however, the abovementioned positive relationship was questioned. Here again, it was the STICH study, which failed to confirm the influence of myocardial viability on revascularization outcome. In fact, the presence of viable myocardium was shown to influence postoperative results on univariate, but not on multivariate analysis. Moreover, various viability assessment tests might have yield various cut-off values for viability parameters, thus often contributing to conflicting or discrepant evaluation criteria. As a consequence, according to later guidelines, assessment of heart muscle viability should no longer be the only test directing therapy selection. Whenever standard viability assessment methods, such as dobutamine stress echocardiography or magnetic resonance imaging are inconclusive in terms of predicting myocardial recovery after revascularization, probably some extensive testing, such as gene expression in myocardial specimens should be considered. Hausmann et al. explored the role of gene expression in myocardial regions with or without predicted recovery potential. Intraoperatively obtained biopsy specimens from ischemic myocardial regions were investigated. It was clearly stated that myocardial areas showing upregulation of antiapoptotic genes occurred to be less prone to postoperative recovery. This study depicted the role of supportive gene testing in referring end-stage CAD patients for proper surgical therapy, i.e., CABG or heart transplantation (33). Taking the above-mentioned into account, current Guidelines do not recommend viability assessment as the only factor determining treatment selection in end-stage CAD patients.

Though the presence of viable myocardium positively influences LVEF, both after conservative and surgical treatment, improving EF is not associated with increased long-term survival. It is the extent of systolic dysfunction and number of stenotic coronaries, rather than heart muscle viability that is associated with postoperative benefits of surgical revascularization (34). Recently published 10-year results of the STICH study confirmed again that improving $\mathrm{EF}$ in patients due to preserved viability was not associated with beneficial long-term effect of CABG (35).

\section{Other treatment modalities}

\section{Heart transplantation}

Since 1967, heart transplantation has become a recognized treatment for patients with end-stage heart failure. According to data published by the International Society for Heart and Lung Transplantation (ISHLT), within the last 3 decades ischemic cardiomyopathy was an underlying cause of end-stage heart failure in approximately $40 \%$ of transplant candidates worldwide and represented one of 2 major indications for heart transplantation in adult population (36,37). Current European guidelines on therapy of heart failure recommend transplantation for end-stage heart failure patients with poor prognosis and no alternative treatment options (38). In end-stage CAD patients, however, surgical revascularization may still be considered a valuable alternative to transplantation and yield promising results, provided that coronary anatomy is suitable for grafting and procedure is associated with acceptable risk (11).

In the real world, heart transplantation is implemented in a relatively small population. The majority of patients with ischemic heart disease, including those with its end- 
stage form, is treated mostly with 'traditional' myocardial revascularization. According to the German Heart Surgery Report from 2018, over 33,000 isolated CABG vs. 312 transplantation procedures were performed in Germany in 2018 (39). Of those transplanted patients, less than 50\% presented with a diagnosis of end-stage CAD. This huge disproportion between the number of patients undergoing CABG and heart transplantation could suggest that even end-stage CAD individuals (presumably included in the 'conventional treatment' group) may exhibit certain characteristics, allowing for safe performance of myocardial revascularization instead of transplant. At the end of the 20th century, some studies aimed at identification of criteria facilitating decision making and referral of end-stage CAD patients for either CABG or heart transplantation. In 1997, Hausmann et al. investigated a population of 514 endstage CAD patients, 225 of them were considered potential transplant candidates. Hausmann and his group (40) emphasized the role of individual patient assessment and presented a set of clinical parameters, enabling proper therapy choice. Of them, the presence of viable myocardium and coronary targets suitable for grafting appeared essential for treatment allocation. Eventually, the results in endstage CAD patients, properly selected for myocardial revascularization, turned out not to be inferior when compared to those of heart transplant recipients. Presence of viable (or 'hibernating) myocardium enabled redirection of end-stage CAD patients from transplant candidacy towards conventional revascularization with promising results (41).

Tjan et al. (42) showed that even patients with severely depressed ventricular function (i.e., $\mathrm{EF}<20 \%$ ) might benefit from myocardial revascularization, as long as viable myocardium and coronary vessels suitable for revascularization were present. In this small population (51 patients of over 7,000 undergoing CABG) 1-year survival was comparable to that of the control transplant group.

\section{Ventricular assist devices}

Though heart transplantation has been a recognized treatment for end-stage heart failure, contemporary growing number of patients requiring transplant cannot be matched by organ availability. According to the Annual Report of the Eurotransplant International Foundation from 2018, only $42 \%$ of patients on waiting list could be transplanted within the first year of listing, whereas 14\% of patients died, awaiting transplant procedure (Eurotransplant International
Foundation Annual Report 2018 (43). Implementation of mechanical heart unloading in these patients has emerged as an alternative, allowing for mortality reduction while on the transplant waiting list $(38,44)$. $\mathrm{LV}$ assist devices (LVAD) have been shown to provide most spectacular reverse remodeling of a failing heart in a long-term perspective, when compared to heart failure pharmacologic treatment or even cardiac resynchronization therapy (45).

Historically, the most efficient unloading could be achieved with pulsatile flow first-generation LVADs. Currently, continuous-flow devices have been increasingly implanted, offering less trauma due to their smaller sizes, better applicability in smaller patients, higher mechanical durability, reduced thrombogenicity and reduced infection rates (46). Hetzer and colleagues presented an extensive experience with rotary blood pumps, implanted in more than 1,000 patients. Though totally changing physiologic flow patterns, rotary devices proved their safety and efficacy, resulting from constant improvements of design, durability and size. Currently, rotary blood pumps have evolved to become a standard of care in heart failure patients, offering satisfactory results and acceptable risk (47).

In recent years, there has been an ongoing debate whether myocardial function in patients with ischemic cardiomyopathy may recover under long-term MCS. Depending on study design, conflicting results regarding potential of 'bridge-to-recovery' concept to generate sustained myocardial recovery in end-stage heart failure have been reported. According to Drakos et al., the abovementioned discrepancies might have been associated with lack of well-designed protocols to assess function of unloaded heart and well-defined criteria of LVADinduced myocardial recovery (48). In 1999 Hetzer and colleagues reported on their initial series of patients with dilatative cardiomyopathy, experiencing myocardial recovery under MCS. The Hetzer group emphasized the role of appropriate duration of unloading, contributing to sustained remodeling and certain molecular changes, such as $\beta$-receptor up-regulation, crucial for promotion of myocardial function improvement (49). With no doubt, the etiology of myocardial dysfunction remains one of the major factors predicting future therapy success. Though ischemic cardiomyopathy was believed to confer less promising and sustained recovery results, recent study by Wever-Pinzon showed that selected patients with ischemiatriggered heart failure presented with potential for durable functional myocardial improvement upon mechanical unloading. In addition, it was suggested LVAD implantation 
could be supplemented by excision of non-viable (scarred) myocardium to eliminate trigger for further remodeling. Mechanical support might also offer a possibility to reassess myocardial viability in order to distinguish areas potentially eligible for future targeted therapies enhancing recovery effect (50). In a recent review paper, Dandel and colleagues emphasized the role of extensive investigations on a molecular level, providing insights into mechanisms of myocardial recovery and reverse remodeling promoted by mechanical heart unloading. Further studies are needed to establish universal criteria allowing for prediction of possible recovery under MCS (51).

\section{Use of intra-aortic balloon pump (LABP)—what has changed?}

For more than 60 years, IABP has been used in cardiovascular medicine as the most widely implemented mechanical cardiac support. Its functional mechanism is based on afterload reduction and augmentation of coronary flow and oxygen supply, resulting in optimization of myocardial performance (52). In recent decades, IABP has been used for treatment of complicated acute myocardial infarction (cardiogenic shock, mechanical complications), as well as prophylactically in high-risk patients or postoperatively in cardiac surgery recipients experiencing difficult separation from cardiopulmonary bypass or low cardiac output syndrome (LCOS).

In case of an acute myocardial infarction with related hemodynamic instability, previous European Guidelines on myocardial revascularization used to recommend routine IABP insertion prior to coronarography (9). This clinical practice, however, became a subject of critical evaluation after publication of a large, randomized Intra-aortic Balloon Pump in Cardiogenic Shock (IABP-SHOCK II Trial), which showed no benefits in terms of reduction of 30 day mortality and improved long-term survival in patients presenting with infarction-related cardiogenic shock $(53,54)$. Thus, according to current guidelines, a routine IABP insertion in acute myocardial infarction complicated by cardiogenic shock is no longer recommended, though intraaortic counterpulsation may confer improvement of certain hemodynamic parameters $(11,55)$.

In cardiac surgery setting, IABP is implemented either prophylactically in patients at risk of postoperative hemodynamic compromise, or postoperatively in case of low cardiac output. Prophylactic IABP implantation has been a subject of discussion since previous and recent studies yield somewhat conflicting conclusions. A recent meta-analysis of randomized trials on prophylactic IABP use not only summarized results of select 9 studies conducted between 1997 and 2013, but also tried to explain the reasons for inconsistences between reports. The main weakness of all trials was a small group size making generation of reasonable conclusions regarding mortality difficult. According to Pilarczyk et al. (56), a group of at least 400 study participants would have been necessary to demonstrate significant differences in survival. In addition, the analysis revealed lack of clearly defined 'highrisk population'. Further, there was a subset of patients undergoing surgery on a not-elective basis, presenting with various degree of hemodynamic instability. Finally, duration of follow-up was relatively short in all trials. Nevertheless, despite the above-mentioned methodological concerns, the analysis suggested beneficial effect of 'prophylactic' IABP implantation in terms of reduced mortality, incidence of postoperative LCOS and length of ICU-stay. There is, however, a need for adequately powered studies to confirm benefits of IABP use prior to surgery (56).

In patients experiencing perioperative LCOS or difficulties in separation from cardio-pulmonary bypass after cardiac surgery, IABP has been the most commonly used form of MCS. According to recent S3 Guidelines for IABP use in cardiac surgery, the above-mentioned conditions affected between $10 \%$ and $45 \%$ cardiac surgery patients (57). In 2002, Baskett et al. (58) analyzed previous reports on experience with IABP implementation in cardiac surgery population. Intra- and postoperative IABP implantation was independently related to poor prognosis and increased mortality. Approximately 40\% patients with intra- and postoperatively implanted IABP required other forms of MCS. According to Baskett et al., at the beginning of the $21^{\text {st }}$ century, IABP treatment for postoperative LCOS appeared very well established, even though its use was based on common practice rather than on strong evidence (58). Contemporary S3 Guidelines recommend prompt IABP implementation for cardio-pulmonary bypass weaning difficulties and/or low cardiac output, though underlying literature evidence derives partially from observational studies or randomized trials of limited quality (57).

IABP implantation allows not only for successful weaning off cardiopulmonary bypass, but due to providing (at least temporary) hemodynamic stabilization, enables evaluation of therapy goals and prognosis. Prediction of possibility for IABP weaning appears crucial for directing future therapy. Bearing in mind that IABP patients might require long- 
term mechanical heart support, Hausmann et al. presented an original scoring system for assessment of IABP weaning possibility. Several clinical parameters, incorporated in the score, occurred to be valuable predictors of chances for IABP cessation and postoperative survival (59). Based on the study by Hausmann and others, current guidelines recommend stepwise IABP weaning under consideration of hemodynamic and lab parameters. In case of IABP inability to provide sufficient circulatory stabilization, scoring systems facilitate decision-making and predict the need for escalation of mechanical cardiac support $(57,60)$.

\section{Conclusions}

Surgical therapy of patients with end-stage CAD remains complex, however the results have improved within the last decades, reflecting progress in operative technique and postoperative care. In this high-risk population CABG still constitutes a valuable treatment option with outcome comparable with that of heart transplantation. SVR, previously widely used and enthusiastically welcomed, have recently became a domain of centers of excellence. Nevertheless, it still constitutes an important adjunct to myocardial revascularization, providing further improvement of myocardial performance.

Existing viable myocardium still plays an important role in prediction of potential myocardial recovery in patients treated with MCS. However, recent studies have shown that EF improvement, resulting from restoration of proper perfusion in viable, hibernating heart muscle, is not associated with increased, long-term survival.

Current evidence for beneficial effect of IABP in myocardial infarction-related cardiogenic shock appears to be limited. In cardiac surgery, however, IABP implantation has remained the most commonly used form of short-term circulatory support.

Recently, some minimally invasive methods for treatment of CAD-associated heart failure have been developed. Though currently not widely implemented, their expansion might be expected, reflecting a contemporary trend towards reduction of procedure invasiveness.

\section{Acknowledgments}

This paper was presented in the joint session of the 27 th Annual Meeting of the ISMCS 2019 and RHICS 17th Expert Forum, October 21-23, 2019, Bologna, Italy. Funding: None.

\section{Footnote}

Provenance and Peer Review: This article was commissioned by the editorial office, Cardiovascular Diagnosis and Therapy for the series "Heart Failure in the Young and Old: Insights into Various Therapies". The article has undergone external peer review.

Conflicts of Interest: All authors have completed the ICMJE uniform disclosure forms (available at http://dx.doi. org/10.21037/cdt-20-284). The series "Heart Failure in the Young and Old: Insights into Various Therapies" was commissioned by the editorial office without any funding or sponsorship. RH served as the unpaid Guest Editor of the series and serves as an unpaid editorial board member of Cardiovascular Diagnosis and Therapy from July 2019 to Jun 2021. The authors have no other conflicts of interest to declare.

Etbical Statement: The authors are accountable for all aspects of the work in ensuring that questions related to the accuracy or integrity of any part of the work are appropriately investigated and resolved.

Open Access Statement: This is an Open Access article distributed in accordance with the Creative Commons Attribution-NonCommercial-NoDerivs 4.0 International License (CC BY-NC-ND 4.0), which permits the noncommercial replication and distribution of the article with the strict proviso that no changes or edits are made and the original work is properly cited (including links to both the formal publication through the relevant DOI and the license). See: https://creativecommons.org/licenses/by-nc-nd/4.0/.

\section{References}

1. Topkara VK, Cheema FH, Kesavaramanujam S, et al. Coronary artery bypass grafting in patients with low ejection fraction. Circulation 2005;112:I344-50.

2. Hausmann H, Siniawski H, Meyer R, et al. Coronary artery bypass grafting in patients with highly impaired ventricular function. Long-term outcome. Dtsch Med Wochenschr 2002;127:2503-7.

3. Alderman EL, Fisher LD, Litwin P, et al. Results of coronary artery surgery in patients with poor left ventricular function (CASS). Circulation 1983;68:785-95.

4. Passamani E, Davis KB, Gillespie MJ, et al. A randomized trial of coronary artery bypass surgery. 
Survival of patients with a low ejection fraction. $\mathrm{N}$ Engl J Med 1985;312:1665-71.

5. McGee EC Jr, McCarthy PM. Do patients with heart failure benefit from coronary artery bypass grafting? Curr Opin Cardiol 2012;27:629-33.

6. Velazquez EJ, Lee KL, Jones RH, et al. Coronary-Artery Bypass Surgery in Patients with Ischemic Cardiomyopathy. N Engl J Med 2016;374:1511-20.

7. Ong AT, Serruys PW, Mohr FW, et al. The SYNergy between percutaneous coronary intervention with TAXus and cardiac surgery (SYNTAX) study: design, rationale, and run-in phase. Am Heart J 2006;151:1194-204.

8. Stone GW, Sabik JF, Serruys PW, et al. EverolimusEluting Stents or Bypass Surgery for Left Main Coronary Artery Disease. N Engl J Med 2016;375:2223-35.

9. Task Force on Myocardial Revascularization of the European Society of Cardiology (ESC) and the European Association for Cardio-Thoracic Surgery (EACTS); European Association for Percutaneous Cardiovascular Interventions (EAPCI), Kolh P, et al. Guidelines on myocardial revascularization. Eur J Cardiothorac Surg 2010;38 Suppl:S1-52.

10. Kolh P, Windecker S, Alfonso F, et al. 2014 ESC/EACTS Guidelines on myocardial revascularization: the Task Force on Myocardial Revascularization of the European Society of Cardiology (ESC) and the European Association for Cardio-Thoracic Surgery (EACTS). Developed with the special contribution of the European Association of Percutaneous Cardiovascular Interventions (EAPCI). Eur J Cardiothorac Surg 2014;46:517-92.

11. Sousa-Uva M, Neumann FJ, Ahlsson A, et al. 2018 ESC/ EACTS Guidelines on myocardial revascularization. Eur J Cardiothorac Surg 2019;55:4-90.

12. Davierwala P, Mohr FW. Five years after the SYNTAX trial: what have we learnt? Eur J Cardiothorac Surg 2013;44:1-3.

13. European Society for Cardio-Thoracic Surgery Official Website. Available online: https://www.eacts.org/ statement-letter-to-excel-trial-principal-investigators/

14. Doenst T, Haverich A, Serruys P, et al. PCI and CABG for Treating Stable Coronary Artery Disease: JACC Review Topic of the Week. J Am Coll Cardiol 2019;73:964-76.

15. Yamaguchi A, Ino T, Adachi $H$, et al. Left ventricular volume predicts postoperative course in patients with ischemic cardiomyopathy. Ann Thorac Surg 1998;65:434-8.

16. Batista RJ, Verde J, Nery P, et al. Partial left ventriculectomy to treat end-stage heart disease. Ann
Thorac Surg 1997;64:634-8.

17. Beyersdorf F. Left ventricular restoration in heart failure: rebirth due to interventional devices? Eur J Cardiothorac Surg 2016;50:589-92.

18. Suma H, Horii T, Isomura T, et al. A new concept of ventricular restoration for nonischemic dilated cardiomyopathy. Eur J Cardiothorac Surg 2006;29 Suppl 1:S207-12.

19. Isomura T, Hirota $M$, Notomi $Y$, et al. Posterior restoration procedures and the long-term results in indicated patients with dilated cardiomyopathy. Interact Cardiovasc Thorac Surg 2015;20:725-31.

20. Dor V, Sabatier M, Di Donato M, et al. Efficacy of endoventricular patch plasty in large postinfarction akinetic scar and severe left ventricular dysfunction: comparison with a series of large dyskinetic scars. J Thorac Cardiovasc Surg 1998;116:50-9.

21. Athanasuleas CL, Buckberg GD, Stanley AW, et al. Surgical ventricular restoration in the treatment of congestive heart failure due to post-infarction ventricular dilation. J Am Coll Cardiol 2004;44:1439-45.

22. Jones RH, Velazquez EJ, Michler RE, et al. Coronary bypass surgery with or without surgical ventricular reconstruction. N Engl J Med 2009;360:1705-17.

23. Buckberg GD, Athanasuleas CL, Wechsler AS, et al. The STICH trial unravelled. Eur J Heart Fail 2010;12:1024-7.

24. Dor V, Civaia F, Alexandrescu C, et al. Favorable effects of left ventricular reconstruction in patients excluded from the Surgical Treatments for Ischemic Heart Failure (STICH) trial. J Thorac Cardiovasc Surg 2011;141:90516, 916.e1-4.

25. Schmidt T, Frerker C, Thielsen T, et al. New evidence for favourable effects on haemodynamics and ventricular performance after Parachute $(\circledR)$ implantation in humans. Eur J Heart Fail 2014;16:1112-9.

26. Dhakal BP, Oliveira GH. Percutaneous Ventricular Restoration with a Partitioning Device for Ischemic Heart Failure Treatment. Curr Heart Fail Rep 2017;14:87-99.

27. Klein P, Agostoni P, van Boven WJ, et al. Transcatheter and minimally invasive surgical left ventricular reconstruction for the treatment of ischaemic cardiomyopathy: preliminary results. Interact Cardiovasc Thorac Surg 2019;28:441-6.

28. Hausmann H, Siniawski H, Hotz H, et al. Mitral valve reconstruction and mitral replacement for ischemic mitral insufficiency. J Card Surg 1997;12:8-14.

29. Hausmann H, Siniawski H, Hetzer R. In: Kouchoukos NT, Blackstone EH, Doty DB (eds.) Kirklin/Barratt-Boyes 
Cardiac Surgery, 3rd Edition, Elsevier Science (USA), 2003:472-82.

30. Hausmann H, Siniawski H, Hetzer R. Mitral valve reconstruction and replacement for ischemic mitral insuffciency: seven years' follow up. J Heart Valve Dis 1999;8:536-42.

31. Rahimtoola SH. A perspective on the three large multicenter randomized clinical trials of coronary bypass surgery for chronic stable angina. Circulation 1985;72:V123-35.

32. Allman KC, Shaw LJ, Hachamovitch R, et al. Myocardial viability testing and impact of revascularization on prognosis in patients with coronary artery disease and left ventricular dysfunction: a meta-analysis. J Am Coll Cardiol 2002;39:1151-8.

33. Hausmann H, Meyer R, Siniawski H, et al. Factors excercising an influence on recovery of hibernating myocardium after coronary artery bypass grafting. Eur J Cardiothorac Surg 2004;26:89-95.

34. Panza JA, Velazquez EJ, She L, et al. Extent of coronary and myocardial disease and benefit from surgical revascularization in ischemic LV dysfunction [Corrected]. J Am Coll Cardiol 2014;64:553-61.

35. Panza JA, Ellis AM, Al-Khalidi HR, et al. Myocardial Viability and Long-Term Outcomes in Ischemic Cardiomyopathy. N Engl J Med 2019;381:739-48.

36. Stehlik J, Edwards LB, Kucheryavaya AY, et al. The Registry of the International Society for Heart and Lung Transplantation: twenty-seventh official adult heart transplant report--2010. J Heart Lung Transplant 2010;29:1089-103.

37. Lund LH, Edwards LB, Kucheryavaya AY, et al. The Registry of the International Society for Heart and Lung Transplantation: Thirtieth Official Adult Heart Transplant Report--2013;focus theme: age. J Heart Lung Transplant 2013;32:951-64.

38. Ponikowski P, Voors AA, Anker SD, et al. 2016 ESC Guidelines for the diagnosis and treatment of acute and chronic heart failure: The Task Force for the diagnosis and treatment of acute and chronic heart failure of the European Society of Cardiology (ESC). Developed with the special contribution of the Heart Failure Association (HFA) of the ESC. Eur J Heart Fail 2016;18:891-975.

39. Beckmann A, Meyer R, Lewandowski J, et al. German Heart Surgery Report 2018: The Annual Updated Registry of the German Society for Thoracic and Cardiovascular Surgery. Thorac Cardiovasc Surg 2019;67:331-44.

40. Hausmann H, Topp H, Siniawski H, et al. Decision- making in end-stage coronary artery disease: revascularization or heart transplantation? Ann Thorac Surg 1997;64:1296-301.

41. Kleikamp G, Posival H, Minami K, et al. Ischemic cardiomyopathy--revascularization vs. transplantation. Eur J Cardiothorac Surg 1997;11 Suppl:S1-4.

42. Tjan TD, Kondruweit M, Scheld HH, et al. The bad ventricle--revascularization versus transplantation. Thorac Cardiovasc Surg 2000;48:9-14.

43. Annual report 2018 ed. by Peter Branger and Undine Samuel, ISBN-EAN: 978-90-71658-38-9.

44. McMurray JJ, Adamopoulos S, Anker SD, et al. ESC guidelines for the diagnosis and treatment of acute and chronic heart failure 2012: The Task Force for the Diagnosis and Treatment of Acute and Chronic Heart Failure 2012 of the European Society of Cardiology. Developed in collaboration with the Heart Failure Association (HFA) of the ESC. Eur J Heart Fail 2012;14:803-69.

45. Uriel N, Sayer G, Annamalai S, et al. Mechanical Unloading in Heart Failure. J Am Coll Cardiol 2018;72:569-80.

46. Kato TS, Chokshi A, Singh P, et al. Effects of continuousflow versus pulsatile-flow left ventricular assist devices on myocardial unloading and remodeling. Circ Heart Fail 2011;4:546-53.

47. Hetzer R, Kaufmann MEng F, Potapov E, et al. Rotary Blood Pumps as Long-Term Mechanical Circulatory Support: A Review of a 15-Year Berlin Experience. Semin Thorac Cardiovasc Surg 2016;28:12-23.

48. Drakos SG, Mehra MR. Clinical myocardial recovery during long-term mechanical support in advanced heart failure: Insights into moving the field forward. J Heart Lung Transplant 2016;35:413-20.

49. Hetzer R, Müller J, Weng Y, et al. Cardiac recovery in dilated cardiomyopathy by unloading with a left ventricular assist device. Ann Thorac Surg 1999;68:742-9.

50. Wever-Pinzon J, Selzman CH, Stoddard G, et al. Impact of Ischemic Heart Failure Etiology on Cardiac Recovery During Mechanical Unloading. J Am Coll Cardiol 2016;68:1741-52.

51. Dandel M, Hetzer R. Recovery of failing hearts by mechanical unloading: Pathophysiologic insights and clinical relevance. Am Heart J 2018;206:30-50.

52. Kantrowitz A. Experimental augmentation of coronary flow by retardation of the arterial pressure pulse. Surgery 1953;34:678-87.

53. Thiele H, Zeymer U, Neumann FJ, et al. Intraaortic 
balloon support for myocardial infarction with cardiogenic shock. N Engl J Med 2012;367:1287-96.

54. Thiele H, Zeymer U, Neumann FJ, et al. Intra-aortic balloon counterpulsation in acute myocardial infarction complicated by cardiogenic shock (IABP-SHOCK II): final 12 month results of a randomised, open-label trial. Lancet 2013;382:1638-45.

55. Unverzagt $S$, Buerke $M$, de Waha A, et al. Intra-aortic balloon pump counterpulsation (IABP) for myocardial infarction complicated by cardiogenic shock. Cochrane Database Syst Rev 2015;(3):CD007398.

56. Pilarczyk K, Boening A, Jakob H, et al. Preoperative intraaortic counterpulsation in high-risk patients undergoing cardiac surgery: a meta-analysis of randomized controlled trials. Eur J Cardiothorac Surg 2016;49:5-17.

57. Pilarczyk K, Bauer A, Boening A, et al. S3-Leitlinie

Cite this article as: Szlapka M, Hetzer R, Ennker J, Hausmann H. Conventional cardiac surgery in patients with end-stage coronary artery disease: yesterday and today. Cardiovasc Diagn Ther 2021;11(1):202-212. doi: 10.21037/cdt-20-284
011/020: Einsatz der intraaortalen Ballongegenpulsation in der Herzchirurgie. AWMF Online Das Portal der wissenschaftlichen Medizin 2015; AWMF-Register Nr. 011/020.

58. Baskett RJ, Ghali WA, Maitland A, et al. The intraaortic balloon pump in cardiac surgery. Ann Thorac Surg 2002;74:1276-87.

59. Hausmann H, Potapov EV, Koster A, et al. Prognosis after the implantation of an intra-aortic balloon pump in cardiac surgery calculated with a new score. Circulation 2002;106:I203-6.

60. Kamiya H, Schilling M, Akhyari P, et al. Outcome analysis for prediction of early and long-term survival in patients receiving intra-aortic balloon pumping after cardiac surgery. Gen Thorac Cardiovasc Surg 2016;64:584-91. 